\title{
The Properties of Immune Complexes Formed by Human Antibodies to Factor VIII
}

\author{
John LAZARChICK and LeON W. HoYer, Hematology Division, Department of \\ Medicine, University of Connecticut School of Medicine, Farmington, \\ Connecticut 06032
}

\begin{abstract}
A B S T R A C T Although human antibodies to Factor VIII inactivate its procoagulant activity, they do not form immunoprecipitates when tested with this antigen. To understand this observation, we have examined the interaction of normal human Factor VIII with four high-titer human anti-Factor VIII, two from transfused hemophiliacs and two "spontaneous" antibodies from nonhemophilic individuals. An estimate of the size of complexes formed by these antibodies has been obtained by agarose gel filtration of mixtures of anti-Factor VIII with cryoprecipitate. Complexed antiFactor VIII was detected by the method of Allain and Frommel: acid dissociation of complexes at pH 3.5.

Complexed anti-Factor VIII was detected in column fractions eluting between the void volume and those which correspond to the elution volume of human IgG. In contrast, Factor VIII procoagulant activity was restricted to void volume fractions when separations were carried out in antigen excess, and free anti-Factor VIII was limited to late-eluting fractions when separations were carried out in antibody excess. A small proportion of the complexed anti-Factor VIII was present in void volume fractions; the quantity was directly related to the ratio of antibody to antigen.

Thus, although some complexed anti-Factor VIII is detected in void volume fractions, as would be expected for complexes formed with a very large plasma protein, most immune complexes elute in fractions that indicate interaction with a smaller antigen. These findings suggest that human anti-Factor VIII inactivates procoagulant activity by forming a complex with a small, apparently univalent, component of Factor VIII. This property may prevent immunoprecipitate formation.
\end{abstract}

Dr. Lazarchick is a Postdoctoral Research Fellow of the National Hemophilia Foundation.

Received for publication 17 January 1977 and in revised form 27 June 1977.

\section{INTRODUCTION}

Although human antibodies to Factor VIII (antihemophilic factor) inactivate its procoagulant activity, the physicochemical nature of this interaction is poorly understood. These antibodies, also designated acquired inhibitors of Factor VIII, have been shown to be IgG in most series (1-3), but the formation of immunoprecipitates and complement fixation have not been identified by standard methods $(3,4)$. Previous studies from this laboratory have sought evidence of immune complex formation using radiolabeled IgG obtained from plasmas of patients with anti-Factor VIII. Immune complexes were not detected in these studies (5). It was concluded that inactivation of Factor VIII procoagulant activity by human anti-Factor VIII is due to antibodies which must have $(a)$ a specific activity which is so great that the low concentration of IgG cannot be detected in complexes by the methods used, or $(b)$ a low affinity so that the complexes are dissociated by the experimental conditions. Alternatively, the human anti-Factor VIII may form complexes with a small univalent portion of the Factor VIII molecule (6).

Allain and Frommel (7) have reported indirect evidence for stable immune complexes between human anti-Factor VIII and Factor VIII: the recovery of antibody activity by heat or acid treatment of antiFactor VIII which had previously been neutralized by addition of excess Factor VIII. More direct evidence of immune complex formation has recently been described by Lavergne et al. (8). Although the recovery of anti-Factor VIII was very low in their experiments, both anti-Factor VIII and Factor VIII were demonstrated in precipitates obtained by addition of polyethylene glycol to mixtures of antigen and antibody. These observations have led us to reexamine the properties of human anti-Factor VIII. Immune complex formation has been verified in these studies, and the 
apparent sizes of these immune complexes were determined by agarose gel filtration.

\section{METHODS}

Factor VIII assay. Factor VIII procoagulant activity was measured by a one-stage method using Factor VIIIdeficient human plasma as substrate (9). Factor VIII-related antigen was determined by a radioimmunoassay as previously described (10). Pooled normal plasma, prepared as previously described $(10)$, served as the standard $(1 \mathrm{U} / \mathrm{ml})$ for measurement of both Factor VIII activity and Factor VIIIrelated antigen.

Anti-Factor VIII measurements. The conditions for antiFactor VIII assay were those suggested by a recent Bethesda Conference (11). In each assay, $0.1 \mathrm{ml}$ of a dilution of the anti-Factor VIII plasma or test material was incubated with $0.1 \mathrm{ml}$ of pooled normal plasma for $2 \mathrm{~h}$ at $37^{\circ} \mathrm{C}$. The Factor VIII procoagulant activity of this mixture was then compared to that of a control tube in which barbital-buffered saline (BBS) ${ }^{1}$ was incubated with the normal plasma. $1 \mathrm{U}$ of anti-Factor VIII activity is defined as that which inactivates $50 \%$ of the procoagulant activity of the control sample during the 2-h incubation (11). When dilutions of antibody were used, the antibody titer was obtained by multiplying the observed value by the dilution factor. The time-dependence of Factor VIII inactivation was established by serial measurements for a mixture of equal volumes of inhibitor plasma and normal plasma held at $37^{\circ} \mathrm{C}$. Samples were removed for Factor VIII assay after 30,60 , and $120 \mathrm{~min}$ of incubation.

Factor VIII sources. Cryoprecipitate was prepared from fresh-frozen normal human plasma obtained from the Connecticut Red Cross Blood Program (12). After thawing, $30-\mathrm{ml}$ aliquots of plasma were stored in $25 \times 100-\mathrm{mm}$ polystyrene tubes at $-70^{\circ} \mathrm{C}$. Cryoprecipitate was obtained by allowing the plasma to thaw at $4^{\circ} \mathrm{C}$ overnight. Cryoprecipitate from one tube was separated by centrifugation at $1000 \mathrm{~g}$ for $10 \mathrm{~min}$ at $4^{\circ} \mathrm{C}$ and was dissolved at $37^{\circ} \mathrm{C}$ in $2.5-4.5$ $\mathrm{ml}$ BBS. Cryoprecipitate was prepared in the same manner from plasma of a patient (H. E.) with severe von Willebrand's disease (13) and a patient with cross-reacting material-positive hemophilia (14). Cross-reacting material-positive hemophilic plasma is that which neutralizes human antibodies to Factor VIII even though it has a very low concentration of Factor VIII procoagulant activity (14).

Human anti-Factor VIII sources. Two of the antibodies (W. D. and D. P.) were obtained from repeatedly transfused patients with severe classic hemophilia. Antibody had been identified in W. D. plasma for over $3 \mathrm{yr}$ at the time the sample was obtained; the D. P. plasma used in these studies was that in which the antibody was first identified. The properties of the A. R. antibody have been reported (14); he had had no abnormal bleeding before the development of the "spontaneous" anti-factor VIII. W. C. plasma was obtained from George King Bio-Medical, Inc. (Salem, N. H.)

Preparation of immune complexes. Immune complexes were prepared by incubating freshly prepared cryoprecipitate with anti-Factor VIII for $2 \mathrm{~h}$ at $37^{\circ} \mathrm{C}$. Small volumes of antibody-containing plasma were added in those studies that were carried out in Factor VIII excess. Antigen excess was verified by demonstrating that the Factor VIII procoagulant activity of the mixture was $>25 \mathrm{U} / 100 \mathrm{ml}$ after the 2-h incuba-

${ }^{1}$ Abbreviations used in this paper: BBS, barbital-buffered saline; DFP, diisopropylfluorophosphate; SBTI, soybean trypsin inhibitor. tion and that there was no residual anti-Factor VIII. In this context, "antigen" designates that immunologic reactivity associated with Factor VIII procoagulant activity; it must be differentiated from Factor VIII-related antigen measured with heterologous antisera $(10,15)$.

Larger volumes of anti-Factor VIII plasma were used to obtain antibody excess in other experiments. Free anti-Factor VIII was present after the 2 -h incubation in these instances. To obtain comparable measurements, the antibody-excess studies for each plasma were carried out using 5 and 10 times the volume of anti-Factor VIII plasma used for studies done in antigen excess. Inactivation of Factor VIII procoagulant activity was verified in each of these experiments: the mixture had $<1 \mathrm{U} / 100 \mathrm{ml}$ at the end of the 2-h incubation.

Incubations of anti-Factor VIII with other materials (cryoprecipitate from hemophilic and von Willebrand's disease plasmas, fractions obtained by gel chromatography, and von Willebrand's disease plasma) were also carried out for $2 \mathrm{~h}$ at $37^{\circ} \mathrm{C}$.

Measurement of complexed anti-Factor VIII. Samples were assayed for complexed anti-Factor VIII by the method of Allain and Frommel (7). After an initial anti-Factor VIII assay to determine if any free antibody was present, samples were adjusted to $\mathrm{pH} 3.5$ by slow addition of $1 \mathrm{~N} \mathrm{HCl}$ during continuous stirring at room temperature. After a 30min incubation at $37^{\circ} \mathrm{C}$, the samples were neutralized by slow addition of $1 \mathrm{~N} \mathrm{NaOH}$ during continuous stirring at room temperature. After the $\mathrm{pH}$ had been returned to $7.2-7.7$, a small amount of denatured and insoluble fibrinogen was removed from samples by centrifugation for $10 \mathrm{~min}$ at $455 \mathrm{~g}$ at room temperature. The anti-Factor VIII in this supernatant fluid was then measured as described above. The quantity of complexed anti-Factor VIII which had been dissociated by acidification was calculated by subtracting the amount of free anti-Factor VIII from the antibody content of the postacidification sample. The sensitivity of this assay is 0.5 antibody $\mathrm{U} / \mathrm{ml}$.

Acidification to pH 3.5 inactivated all Factor VIII procoagulant activity of plasmas and other samples. To be certain that acidification to $\mathrm{pH} 3.5 \mathrm{did}$ not have any nonspecific anticoagulant effect, samples of cryoprecipitate and gel-filtration column fractions were carried through the acidification-neutralization cycle in the absence of added anti-Factor VIII. There was no apparent (artifactual) antiFactor VIII activity after the materials had been returned to $\mathrm{pH}$ 7.2-7.7. The ability of Factor VIII to neutralize human anti-Factor VIII is completely lost during this acidification (7). Thus, dissociated antibody can not recombine with Factor VIII after the $\mathrm{pH}$ is returned to 7.2-7.7.

Human anti-Factor VIII was stable at $\mathrm{pH} 3.5$ in our experiments as it was in the studies reported by Allain and Frommel (7). In eight separate experiments, anti-Factor VIII plasmas adjusted to $\mathrm{pH} 3.5$, incubated, and neutralized as noted above had $94-105 \%$ of the antibody activity of control samples treated in the same way except that they were not acidified and then neutralized. The titer of anti-Factor VIII in fractions separated by gel filtration was also unaffected by the acidification-neutralization cycle.

Agarose gel filtration. All separations were carried out at room temperature using a $1.6 \times 87-\mathrm{cm}$ column of $6 \%$ agarose (Sepharose 6B, Pharmacia Fine Chemicals, Div. of Pharmacia Inc., Piscataway, N. J.) equilibrated with BBS Upward flow elution was maintained at $20 \mathrm{ml} / \mathrm{h}$ using a peristaltic pump, and $1.8-\mathrm{ml}$ fractions were collected The void volume $(54 \mathrm{ml})$ was determined using blue dextran 2000 (Pharmacia Fine Chemicals). The protein concentration of column fractions was estimated by measurement of the optical density at $280 \mathrm{~nm}$. IgG was measured by radial 
immunodiffusion (16) using Hyland Immuno-Plates (Hyland Div., Travenol Laboratories, Inc., Costa Mesa, Calif.).

For some studies, column fractions were pooled after the protein concentrations were measured. The combination of tubes into these pools followed the pattern noted in Fig. 3. Pool I included the $11.5-14.3 \mathrm{ml}$ in the void volume protein peak; pool II included the $10.4-14.4 \mathrm{ml}$ in tubes with minimal protein content between the first two peaks; pool III included the $11.8-16.1 \mathrm{ml}$ of the first half of the second protein peak; pool IV included the 12.9-15 ml of the second half of the second protein peak; and pool $\mathrm{V}$ included the first $14.5-18.8 \mathrm{ml}$ of the third protein peak.

Two rechromatography experiments were carried out after the proteins of pools I-III were concentrated by addition of an equal volume of saturated ammonium sulfate. After a 30 -min incubation at room temperature, the precipitated proteins were separated by centrifugation at $25^{\circ} \mathrm{C}$ $(7,000 \mathrm{~g}$ for $15 \mathrm{~min})$. The precipitated proteins were then dissolved in BBS and were extensively dialyzed against BBS.

Buffers. The barbital-buffered saline (BBS) was prepared by adding $7.3 \mathrm{~g} \mathrm{NaCl}, 2.76 \mathrm{~g}$ barbital, $2.06 \mathrm{~g}$ sodium barbital, $5 \mathrm{~g}$ - -aminocaproic acid, and $0.2 \mathrm{~g}$ sodium azide to sufficient deionized water to make 1 liter; the $\mathrm{pH}$ was then adjusted to 7.5 at $22^{\circ} \mathrm{C}$.

Protease inhibitors were incorporated in these buffers in two experiments. In one, cryoprecipitate dissolution and chromatography was carried out in BBS to which diisopropylfluorophosphate (DFP) (Sigma Chemical Company, St. Louis, Mo.) was added at a final concentration of $0.002 \mathrm{M}$ (17). In the second experiment, $100 \mathrm{ml}$ of fresh normal human blood was obtained by venipuncture using the double-syringe technique. It was immediately added to chilled silicone-coated polycarbonate tubes containing $1 / 50 \mathrm{vol}$ of a mixture of $0.5 \mathrm{M}$ sodium citrate, $\mathrm{pH} 5.0,0.5$ $\mathrm{mg} / \mathrm{ml}$ soybean trypsin inhibitor (SBTI) (Sigma Chemical Company, St. Louis, Mo.), $5 \mathrm{mg} / \mathrm{ml} \epsilon$-aminocaproic acid, and $4 \mathrm{U} / \mathrm{ml}$ hirudin (Pentapharm Ltd., Basel, Switzerland) (17). The anticoagulated whole blood was centrifuged at $1000 \mathrm{~g}$ for $15 \mathrm{~min}$ at $4^{\circ} \mathrm{C}$, the plasma was transferred to siliconecoated polypropylene tubes, and DFP was added at a final concentration of $0.002 \mathrm{M}$. The tubes were then quickfrozen in acetone-dry ice and allowed to thaw overnight at $4^{\circ} \mathrm{C}$. Cryoprecipitate separated as noted above was dissolved in BBS to which had been added $10 \mu \mathrm{g} / \mathrm{ml}$ SBTI, 0.2 $\mathrm{U} / \mathrm{ml}$ hirudin, and $0.002 \mathrm{M}$ DFP.

\section{RESULTS}

The properties of the four antibodies to Factor VIII used in this study are summarized in Table I. Each antibody inactivated $>99 \%$ of the Factor VIII procoagulant activity of normal plasma if added in sufficient quantity. Time-dependent Factor VIII inactivation was demonstrated in the three plasmas which were tested for this property (W. C., W. D., and A. R.).

Evidence for immune complex formation was obtained by incubating each anti-Factor VIII plasma with sufficient normal plasma to ensure conditions of antigen excess. After a 2 -h incubation at $37^{\circ} \mathrm{C}$, each mixture had easily measurable Factor VIII procoagulant activity $(<25 \mathrm{U} / 100 \mathrm{ml})$, and there was no residual free anti-Factor VIII. A short incubation at pH 3.5 inactivated all Factor VIII activity, and it was
TABLE I

Properties of Human Antibodies to Factor VIII

\begin{tabular}{llcc}
\hline & \multicolumn{3}{c}{ Anti-Factor VIII } \\
\cline { 2 - 4 } Patient & Type & Titer & Dissociable* \\
\hline & & Bethesda U/ml & $\%$ \\
W. C. & Spontaneous & 3,800 & 53,68 \\
A. R. & Spontaneous & 560 & 34,35 \\
W. D. & Hemophilic & 190 & 47,49 \\
D. P. & Hemophilic & 220 & 40,47 \\
\hline
\end{tabular}

* Dilutions of antisera were incubated with excess normal cryoprecipitate, the mixture was incubated for $2 \mathrm{~h}$ at $37^{\circ} \mathrm{C}$, and residual Factor VIII activity was demonstrated (30-75 $\mathrm{U} / 100 \mathrm{ml}$ ). The mixture was then incubated at $\mathrm{pH} 3.5$ to dissociate the complexes, and the anti-Factor VIII titer was measured. The percentage of dissociability was calculated by reference to the antibody titer of a mixture of antisera and BBS in place of the cryoprecipitate. Values for two separate determinations are given.

then possible to identify anti-Factor VIII antibody which had been present in immune complexes. Between 34 and $68 \%$ of the anti-Factor VIII added to the cryoprecipitate-antibody mixture was recovered as dissociable antibody after the acidification-neutralization cycle (Table I). This recovery of anti-Factor VIII from immune complexes formed in antigen excess is comparable to that reported by Allain and Frommel (7). The remaining anti-Factor VIII is presumed to have been incorporated in immune complexes which were not dissociated at $\mathrm{pH} 3.5$. However, it was not possible to recover this antibody by reduction of the $\mathrm{pH}$ to below 3.5, because the anti-Factor VIII was unstable if additional acidification was attempted, e.g., only $15 \%$ of anti-Factor VIII activity was retained when antibody plasmas were incubated alone at $\mathrm{pH} 2.5$ for $30 \mathrm{~min}$ at room temperature.

The gel-filtration properties of anti-Factor VIII alone were determined as a first step toward the characterization of immune complexes (Fig. 1). The separation summarized in this figure employed the largest quantity of antibody used in any experiment (760 Bethesda U, $0.2 \mathrm{ml}$ of W. C. plasma). AntiFactor VIII activity was restricted to fractions which elute late; no activity was detected in the void volume fractions. Assay of every column fraction in two separate experiments indicated that free anti-Factor VIII eluted in fractions slightly earlier than the bulk of IgG. Incubation of $0.2 \mathrm{ml} \mathrm{W}$. C. plasma with cryoprecipitate prepared from $30 \mathrm{ml}$ of von Willebrand's disease plasma did not affect the elution pattern of anti-Factor VIII. The elution pattern of free antibody was the same in that experiment as it was when $0.2 \mathrm{ml}$ of $\mathrm{W}$. C. plasma was chromatographed alone (Fig. 1). Acidification (to $\mathrm{pH}$ 3.5) and neutralization of these column 


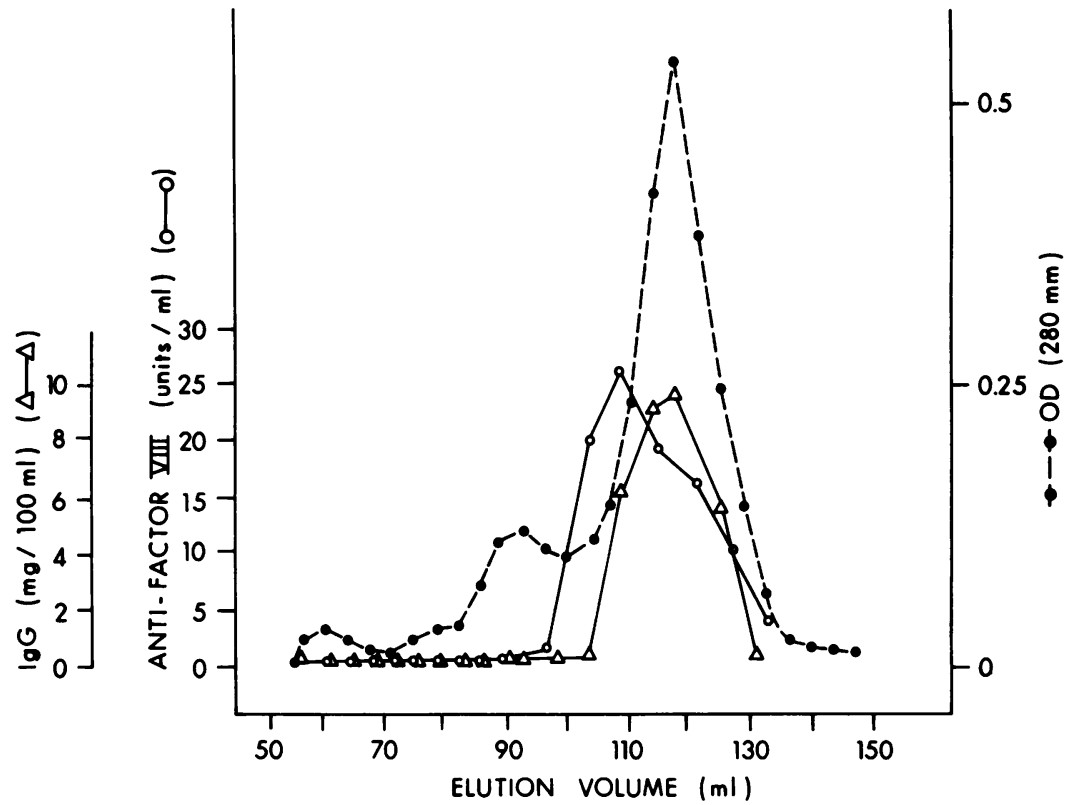

FIGURE 1 Gel filtration pattern of human anti-Factor VIII. Antibody activity $(\mathrm{O}-\mathrm{O})$ is limited to late-eluting fractions $(100-130 \mathrm{ml})$ in this separation of $0.2 \mathrm{ml}$ of W. C. plasma on a $1.6 \times 87-\mathrm{cm}$ column of $6 \%$ agarose. The IgG elution pattern is shown for comparison $(\Delta-\Delta)$.

fractions did not inhibit or enhance their anti-Factor VIII activities.

Factor VIII procoagulant activity and Factor VIIIrelated antigen had very different gel filtration properties from those of anti-Factor VIII. Both measures were maximal in the void volume fractions when cryoprecipitate from normal plasma was chromatographed alone on the same $6 \%$ agarose column (Fig. 2).

Mixtures of anti-Factor VIII with cryoprecipitate were then examined to determine the properties of the immune complexes which were formed during a 2 -h incubation at $37^{\circ} \mathrm{C}$. The initial studies were carried out in antibody excess and a representative experiment is illustrated in Fig. 3. Free anti-Factor VIII was present in the same late-eluting fractions as it was when no Factor VIII was added (i.e., Fig. 1). Dissociable anti-Factor VIII was also detected, however, when anti-Factor VIII was incubated with cryoprecipitate before gel filtration. Complexed anti-Factor VIII was identified at the void volume and in fractions between the void volume and those in which free anti-Factor VIII was eluted.

A more extensive study of the elution pattern of these complexes was then carried out so that their size distribution could be established. To carry out a sufficiently large number of studies in which both free and dissociable antibody were measured, assays were carried out on pooled fractions rather than for each tube (see Methods). The free anti-factor VIII and the acid ( $\mathrm{pH}$ 3.5)-dissociable anti-Factor VIII content of each pool were determined. Between three and six gel filtration studies were carried out with each antiFactor VIII plasma. In general, similar patterns were obtained with the different antibodies; the data for three studies for each plasma are listed in Table II.

Mixtures prepared in antigen excess provided the most direct demonstration of the properties of immune complexes in that no free anti-Factor VIII was present. In these studies, a limited quantity of antibody $(0.02-0.2 \mathrm{ml} ; 23-76$ Bethesda $U$ of anti-Factor VIII) was incubated with cryoprecipitate prepared from $30 \mathrm{ml}$ of normal human plasma $(12-16 \mathrm{U}$ of Factor VIII activity in $2.8-4.5 \mathrm{ml}$ ). The details of these antigen-excess studies are given in the first line of data for each antibody in Table II. Factor VIII procoagulant activity was identified in early fractions (pools I and II) when these mixtures were analyzed by agarose gel filtration. Free antibody was not present in any fractions in these studies. Acid-dissociable antibody was identified in both large and small complexes, however, when W. C. plasma was used and was present in late-eluting complexes formed by A. R. plasma (Fig. 4). Dissociable anti-Factor VIII was not identified in eluted fractions when $W$. D. and D. P. plasmas were used. The failure to detect dissociable complexes in these two separations was due to the insensitivity of the assay for small amounts of antibody in gel filtration experiments. Complexed anti-Factor VIII was recovered in good yield when assays were carried out directly on mixtures of these antibodies with cryoprecipitate (Table I).

A second set of experiments examined the properties 


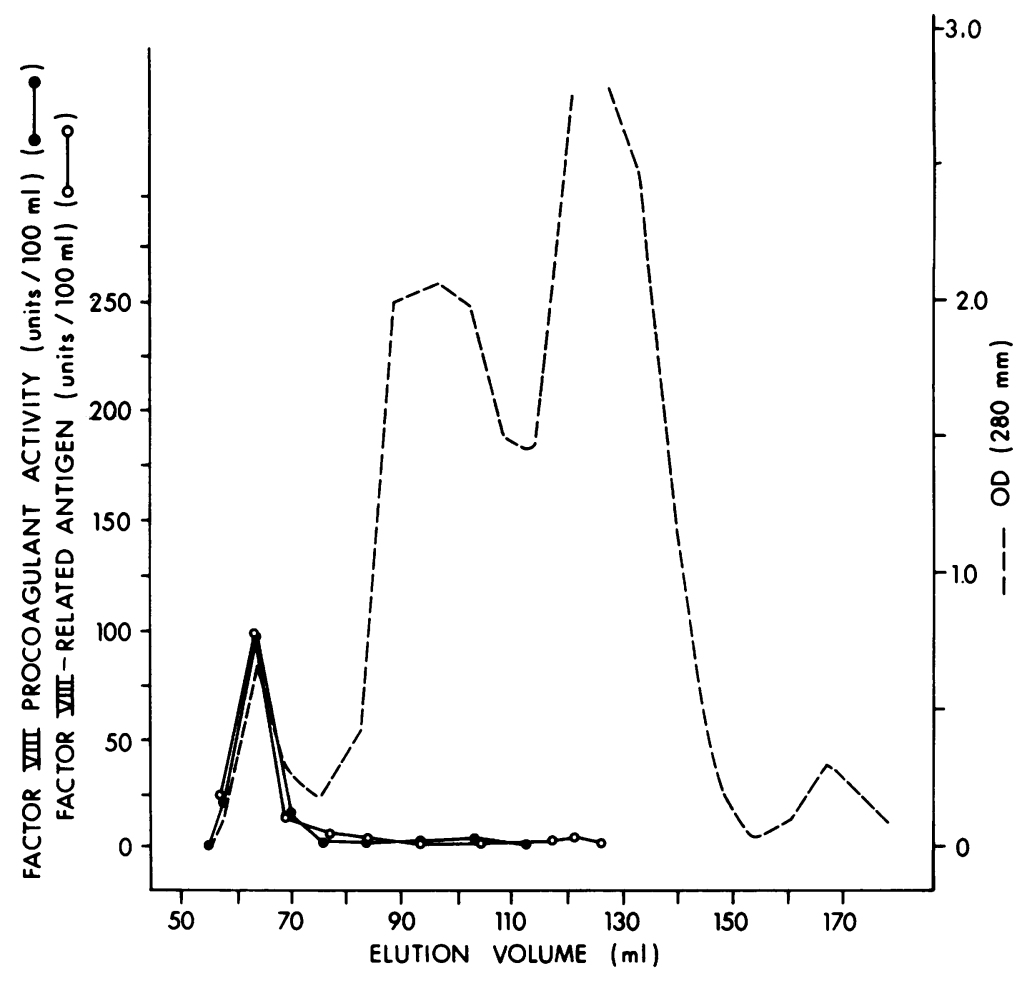

FIGURE 2 Gel filtration pattern of normal cryoprecipitate. Factor VIII procoagulant activity and Factor VIII-related antigen are both confined to the void volume fractions in this separation of $3.1 \mathrm{ml}$ of cryoprecipitate on a $1.6 \times 87-\mathrm{cm}$ column of $6 \%$ agarose.

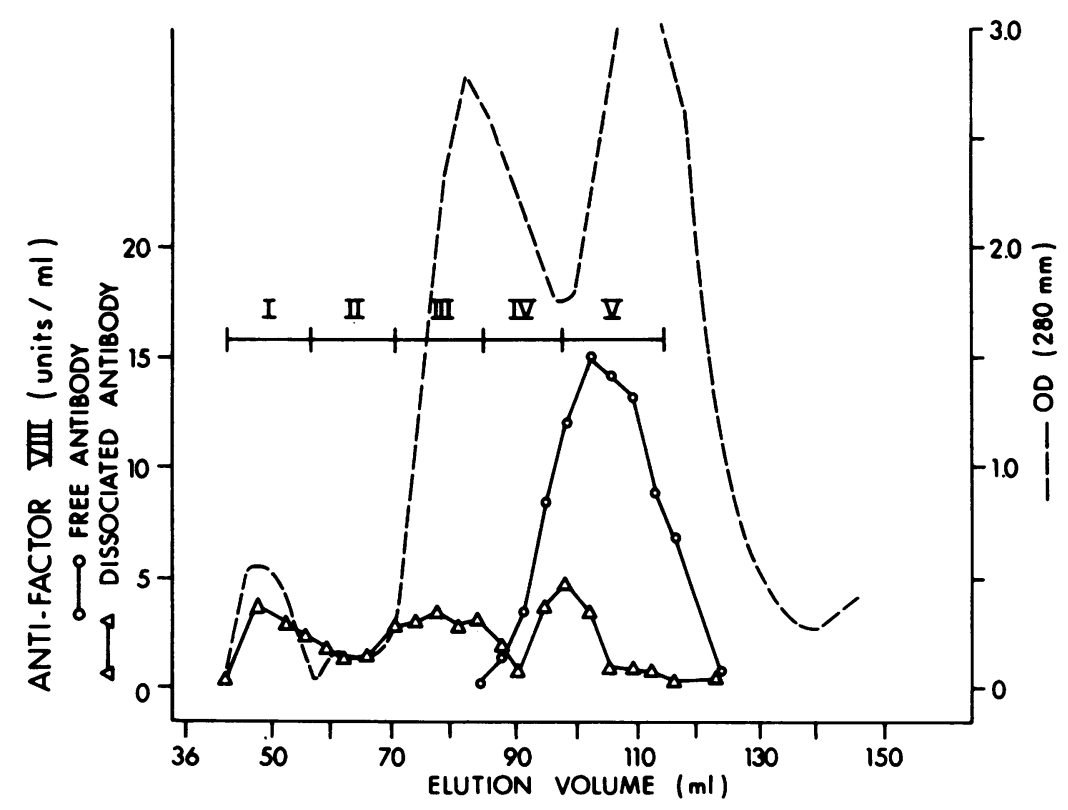

FIGURE 3. Gel filtration pattern of $0.1 \mathrm{ml} \mathrm{W}$. C. anti-Factor VIII after incubation with $2.4 \mathrm{ml}$ normal cryoprecipitate. The separation was carried out on a $1.6 \times 83-\mathrm{cm}$ column of $6 \%$ agarose. The anti-Factor VIII titers of individual $1.8-\mathrm{ml}$ fractions are indicated; values are given for free antibody and for complexed anti-VIII which was dissociated at pH 3.5. Pools I-V in other experiments correspond to the fractions indicated in this figure. 
TABLE II

Recovery of Anti-Factor VIII after Gel Chromatography

\begin{tabular}{|c|c|c|c|c|c|}
\hline $\begin{array}{c}\text { Antibody } \\
\text { source }\end{array}$ & $\begin{array}{l}\text { Antibody } \\
\text { added* } \\
\text { (a) }\end{array}$ & $\begin{array}{c}\text { Free } \\
\text { antibody } \\
\text { (b) }\end{array}$ & $\begin{array}{c}\text { Complexed } \\
\text { antibody } \\
(a-b)\end{array}$ & $\begin{array}{c}\text { Antibody } \\
\text { dissociated } \\
\text { at pH } 3.5 \\
\text { (c) }\end{array}$ & 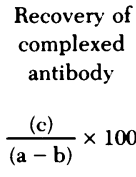 \\
\hline \multicolumn{6}{|c|}{ units } \\
\hline \multirow[t]{3}{*}{ W. C. } & 76 & 0 & 76 & 28 & 36 \\
\hline & 380 & 79 & 301 & 164 & 54 \\
\hline & 760 & 558 & 202 & 265 & 131 \\
\hline \multirow[t]{3}{*}{ A. R. } & 67 & 0 & 67 & 24 & 36 \\
\hline & 280 & 133 & 147 & 48 & 33 \\
\hline & 420 & 308 & 112 & 41 & 37 \\
\hline \multirow[t]{3}{*}{ W. D. } & 23 & 0 & 23 & 0 & 0 \\
\hline & 95 & 8 & 87 & 54 & 62 \\
\hline & 285 & 197 & 88 & 56 & 64 \\
\hline \multirow[t]{3}{*}{ D. P. } & 44 & 0 & 44 & 0 & 0 \\
\hline & 220 & 62 & 158 & 42 & 27 \\
\hline & 440 & 159 & 281 & 91 & 32 \\
\hline
\end{tabular}

* Each antibody $(0.02-2.0 \mathrm{ml})$ was incubated with $12-16 \mathrm{U}$ of Factor VIII activity present in $2-5 \mathrm{ml}$ of cryoprecipitate from normal human plasma.

of complexes prepared in antibody excess (Table II: the second and third lines of data for each antibody). No Factor VIII procoagulant activity was detected after the 2-h incubation, and residual free anti-factor VIII was always present. Both large and small immune complexes were present when the mixtures were

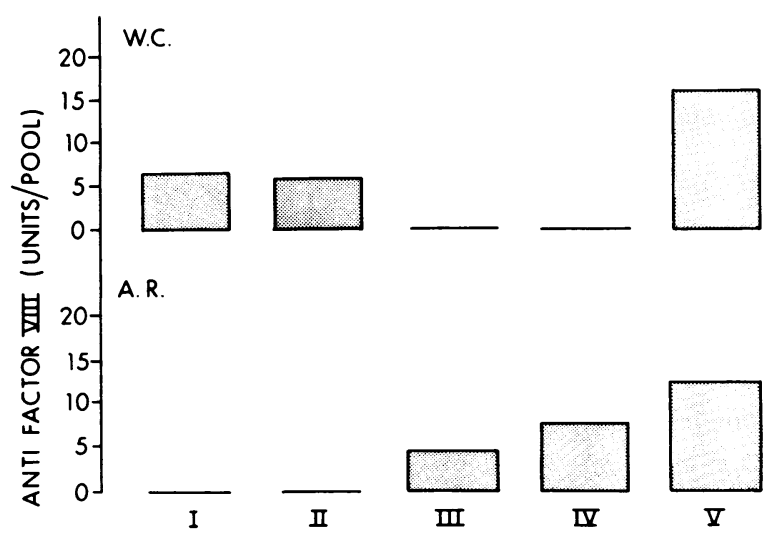

FIGURE 4 Elution properties of complexed anti-Factor VIII in the presence of antigen excess. The five pools correspond to agarose gel filtration fractions indicated in Fig. 3. Mixtures of anti-Factor VIII (76 Bethesda U of W. C. plasma and 67 units of $\mathrm{A}$. R. plasma) were incubated for $2 \mathrm{~h}$ at $37^{\circ} \mathrm{C}$ with cryoprecipitate ( 12 and 16 units of Factor VIII procoagulant activity) before gel filtration on a $1.6 \times 83-\mathrm{cm}$ column of $6 \%$ agarose. No free antibody was present in any of the fractions; antibody values are those of the pools after the complexes had been dissociated at $\mathrm{pH} 3.5$. analyzed by agarose gel chromatography after the 2-h incubation (Fig. 5). Free antibody was present in the late-eluting fractions (pools IV and V) in each case and a small amount of free W. C. anti-Factor VIII was detected in pool III. This was not expected because the elution volume corresponding to pool III did not have any free antibody when $0.2 \mathrm{ml} \mathrm{W}$. C. plasma (760 $\mathrm{U}$ of antibody activity, the largest amount present in any study) was chromatographed without a previous incubation with a Factor VIII source (Fig. 1).

The distribution of dissociable anti-Factor VIII in large (pools I and II) and small (pools IV and V) complexes was related to the ratio of antibody to antigen (Fig. 6). The amount of dissociable (complexed) antiFactor VIII in the early-eluting fractions was directly related to this ratio in each case. The amount of dis-

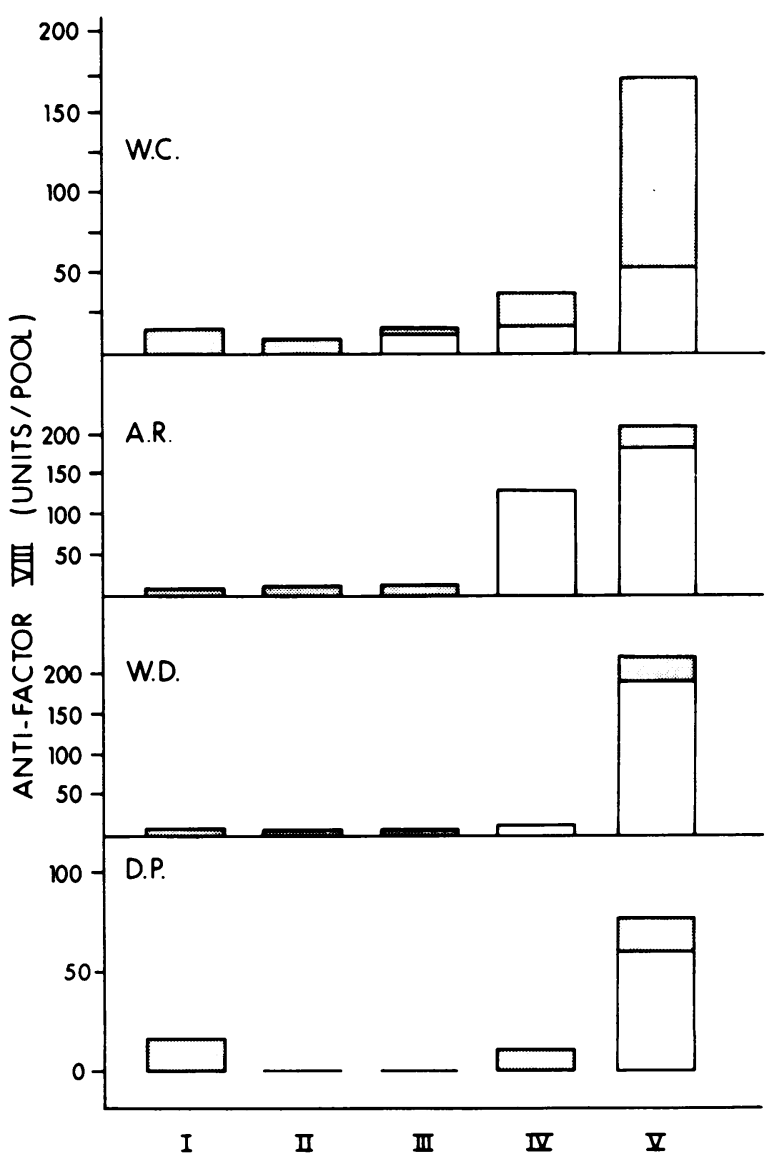

FIGURE 5 Elution properties of anti-Factor VIII in the presence of excess antibody. The five pools correspond to the agarose gel filtration fractions indicated in Fig. 3. Before gel filtration on a $1.6 \times 83-\mathrm{cm}$ column of $6 \%$ agarose, mixtures of anti-Factor VIII (220-380 Bethesda U) were incubated for $2 \mathrm{~h}$ at $37^{\circ} \mathrm{C}$ with sufficient cryoprecipitate that the ratio of antibody (Bethesda units) to units of Factor VIII procoagulant activity was 21-25. Free anti-Factor VIII is indicated by the open bars; antibody dissociated from complexes at $\mathrm{pH} 3.5$ is shown as hatched bars. 


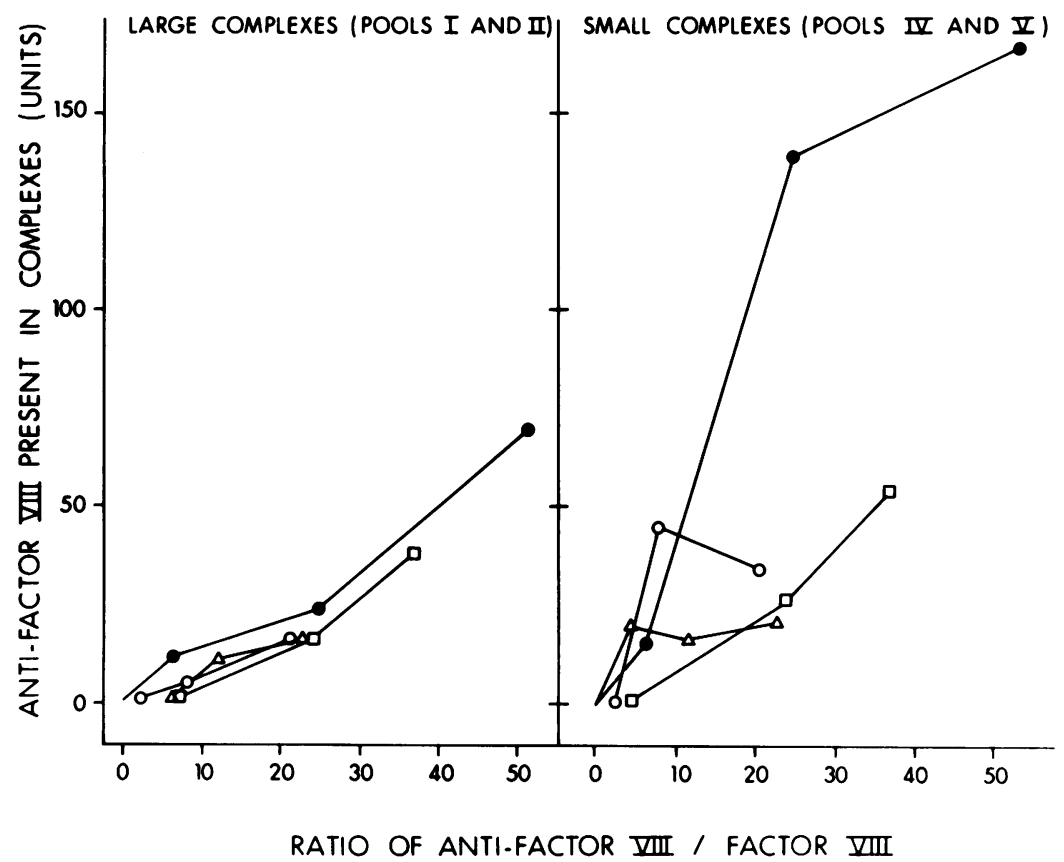

FIGURE 6 The elution pattern of complexed anti-Factor VIII. The left panel indicates the amount of anti-Factor VIII dissociated at pH 3.5 in pools I and II (large complexes); the right panel indicates the amount of complexed antibody in pools IV and V (small complexes). Data are given for plasmas W. C. $(-O)$; A. R. $(\Delta-\Delta)$; W. D. $(\bigcirc-O)$; and D. P. $(\square-\square)$.

sociable antibody in late-eluting complexes followed a somewhat different pattern. The amount of complexed anti-Factor VIII in these fractions did not increase beyond a plateau value as increasing amounts of W. D. and A. R. plasma were added. In contrast, the amount of late-eluting complexed anti-Factor VIII was related to the quantity of D. P. and W. C. plasma added for all ratios that were tested.

The properties of acid-dissociated anti-Factor VIII were then examined by rechromatography. In these studies, pool I-III proteins were concentrated by addition of an equal volume of saturated ammonium sulfate after the acidification-neutralization cycle had identified dissociated anti-Factor VIII. In one experiment, the acid-dissociated anti-Factor VIII (38 U in $1.7 \mathrm{ml}$ ) was incubated with $1 \mathrm{ml}$ plasma from a patient with severe von Willebrand's disease before rechromatography. Free anti-Factor VIII (21.5 U) was present in the pool V (IgG) fractions, and no dissociable antibody was present in any of the pools.

In contrast, acid-dissociated pool I-III antibody (46 $\mathrm{U}$ in $2.5 \mathrm{ml}$ ) had a different elution pattern on rechromatography when it was incubated with 2.8 $\mathrm{ml}$ of cryoprecipitate from $30 \mathrm{ml}$ normal plasma (a mixture in which all anti-Factor VIII was neutralized by the Factor VIII which was added). Dissociable antiFactor VIII was present in both large (pool I and II) and small (pool IV and V) complexes in this experiment. The overall recovery of antibody was $83 \%$; the distribution in pools $\mathrm{I}-\mathrm{V}$ was $17,0,5,10$, and $6 \mathrm{U}$, respectively. This rechromatography identified heterogeneity in antibody dissociated from large complexes; it can form both large and small complexes with fresh Factor VIII.

Preliminary studies of complex formation were also carried out with cryoprecipitate prepared from CRMpositive hemophilic plasma. Because this material neutralizes human anti-Factor VIII even though it lacks Factor VIII procoagulant activity (13), it was of interest to know if complexes could be identified when cryoprecipitate prepared from $25 \mathrm{ml}$ plasma (3.4 $\mathrm{ml}$ final volume) was incubated with anti-Factor VIII. The volume of $\mathrm{W}$. C. plasma was chosen to assure antibody excess: $0.1 \mathrm{ml}$ containing $380 \mathrm{U}$ anti-Factor VIII. No dissociable antibody was recovered in pools I or II; dissociable anti-Factor VIII was identified in late eluting complexes $(3,12$, and $60 \mathrm{U}$ in pools III, IV, and V); and free anti-Factor VIII was present in pools IV and V (6 and $150 \mathrm{U}$ ).

It was recognized that measurement of complexed anti-Factor VIII would not be valid if nonspecific anticoagulant activity was caused by acidification of plasma or column fractions. This possibility was examined in several studies. In one, column fractions 
from a separation such as that of Fig. 2 were carried through the acidification-neutralization cycle. No anticoagulant (antibody) activity could be detected using the standard anti-Factor VIII assay. In another study, $1 \mathrm{ml}$ of cryoprecipitate was treated in the same way; again there was no detectable anticoagulant activity.

Inasmuch as proteolytic cleavage of antibodyFactor VIII complexes might lead to the presence of complexed anti-Factor VIII in late-eluting fractions, $0.002 \mathrm{M}$ DFP was added to the mixtures and elution buffers used in one experiment. Among its properties, this protease inhibitor prevents thrombin activation of Factor VIII (17), a process which has been shown to affect the gel filtration pattern of Factor VIII procoagulant activity (18). W. C. antibody (126 U) in 0.5 $\mathrm{ml} \mathrm{BBS}$ was brought to $0.002 \mathrm{M}$ DFP before the addition of cryoprecipitate prepared from $30 \mathrm{ml}$ of normal plasma (the $5-\mathrm{ml}$ vol was also brought to $0.002 \mathrm{M}$ DFP). This mixture contained no free anti-Factor VIII at the end of the standard 2-h incubation, and none was detected in the fractions obtained by a gel filtration separation in which $0.002 \mathrm{M}$ DFP was included in the BBS used for elution. The recovery $(60 \%)$ and distribution of complexed anti-Factor VIII in pools I-V $(32,13,13,9$, and $19 \mathrm{U}$, respectively) was similar to that of experiments in which no DFP was present (Fig. 5).

It was also considered possible that proteolytic cleavage of Factor VIII could have occurred before the gel filtration. A complex mixture of protease inhibitors, was, therefore, added to freshly-drawn blood, and effective concentrations of DFP, $\epsilon$-aminocaproic acid, SBTI, and hirudin were maintained during the cryoprecipitate preparation and immune interaction $(17,19)$. W. C. antibody (95 $\mathrm{U}$ in $0.025 \mathrm{ml}$ ) was added to the dissolved cryoprecipitate prepared from fresh normal human plasma following the special procedure noted in Methods, the 3-ml vol contained $24 \mathrm{U}$ of Factor VIII activity before the addition of antibody. At the end of the standard 2-h incubation, the mixture had a Factor VIII activity of $8 \mathrm{U} / 100 \mathrm{ml}, 1 \%$ of the starting level. Gel chromatography using $6 \%$ agarose was carried out in the standard manner except that a different agarose source was used (Bio-Gel A-5M, BioRad Laboratories, Richmond, Calif.), and the BBS elution buffer contained $0.002 \mathrm{M}$ DFP and $10 \mu \mathrm{g} / \mathrm{ml}$ SBTI. The mixture contained no free anti-Factor VIII at the end of the incubation, and none was detected in the gel filtration fractions. Factor VIII activity was detected only in void volume fractions corresponding to pool $\mathrm{I}$. The recovery $(61 \%)$ and distribution of complexed anti-Factor VIII in pools I-V $(18,14,10,0$, and $17 \mathrm{U}$, respectively) was similar to that of experiments in which there were no protease inhibitors (Fig. 5, Table II).

\section{DISCUSSION}

These studies document the formation of stable immune complexes by human antibodies to Factor VIII. In general, the properties of antibodies from transfused hemophilic patients were the same as those from nonhemophilic patients who had developed spontaneous inhibitors. The recovery of anti-Factor VIII by acidification of mixtures prepared in antigen excess confirms the findings of Allain and Frommel (7). This method has proved to be a highly reproducible and relatively sensitive way to examine the properties of human anti-Factor VIII.

In contrast to the apparent large size of Factor VIII on gel chromatography (Fig. 2), immune complexes formed by anti-Factor VIII had a heterogeneous elution pattern on agarose gel filtration (Fig. 3). While the expected large (void volume) complexes could be detected when separations were carried out in antibody excess, some complexed anti-Factor VIII was also identified in later-eluting fractions. Furthermore, studies carried out in antigen excess demonstrated predominantly late-eluting complexed anti-Factor VIII (Fig. 4). These results indicate a fragmentation of Factor VIII in the presence of human antibody, an unexpected finding in the light of the homogeneous properties of Factor VIII when chromatographed alone under otherwise identical conditions (Fig. 2). These findings suggest that the portion of Factor VIII that reacts with human anti-Factor VIII may become separated from the rest of this large protein under certain conditions. The broad elution pattern of complexed anti-Factor VIII has prevented more specific characterization of the exact size of these immune complexes (Fig. 3).

Although the nature of Factor VIII is still a subject of controversy $(20,21)$, studies from this and other laboratories have suggested that both plasma Factor VIII and highly purified Factor VIII can be dissociated in the presence of high ionic strength buffers (22-24). Dialysis of Factor VIII in $1.0 \mathrm{M} \mathrm{NaCl}$ or $0.25 \mathrm{M}$ $\mathrm{CaCl}_{2}$, followed by gel filtration on agarose or by sucrose density gradient centrifugation, has resulted in the separation of two components: a high molecular weight material which retains Factor VIII-related antigenic properties and ristocetin cofactor activity but lacks procoagulant activity; and a low molecular weight material which has Factor VIII procoagulant but lacks ristocetin cofactor activity and does not form immunoprecipitates with rabbit anti-Factor VIII. The identification of the low molecular weight procoagulant activity as Factor VIII has been confirmed by the inhibition of its coagulant activity by human antiFactor VIII (23) and by the ability of thrombin to activate this material $(18,25)$. Because of its very low protein content, this low molecular weight Factor VIII 
coagulant activity has not yet been characterized chemically. It behaves as a protein of 100,000-200,000 daltons on agarose gel filtration and has a calculated sedimentation coefficient of $6.7 \mathrm{~S}$ on sucrose gradient centrifugation (26). Bloom et al. have also demonstrated that low molecular weight Factor VIII coagulant activity neutralizes human antibodies to Factor VIII (27).

In view of these properties of Factor VIII, it seems likely that the human antibodies react with the smaller component and that the association of the larger and smaller components of Factor VIII is affected by this immune interaction. This formulation is consistent with the attribution of Factor VIII procoagulant activity to the smaller component and the limited effects of human antibodies, i.e., they inactivate procoagulant activity but do not interfere with ristocetin cofactor activity or other measurements of Factor VIII plateletrelated activity $(2,28,29)$. An alternative possibility, proteolytic cleavage of IgG-Factor VIII complexes during the incubation or chromatography, has been excluded by demonstrating that the inclusion of $0.002 \mathrm{M}$ DFP alone (17) or a combination of potent protease inhibitors $(0.002 \mathrm{M}$ DFP, $10 \mu \mathrm{g} / \mathrm{ml}$ SBTI, and $0.2 \mathrm{U} / \mathrm{ml}$ hirudin) (19) does not affect the elution pattern of the complexed anti-Factor VIII.

These studies may clarify previously inexplicable properties of human antibodies to Factor VIII. The limited formation of large immune complexes, even in the presence of marked antibody excess, may be the reason why immunoprecipitates are not formed by even the highest titer human anti-Factor VIII. Although these experiments have not established the size of the smallest complex that is formed by human antiFactor VIII, the elution pattern (e.g., Fig. 3) indicates that it is smaller than fibrinogen (i.e., it is $<340,000$ daltons). This indicates that the Factor VIII component that interacts with human antibodies is univalent because it is unlikely that two IgG molecules could be included in a complex of that size. This conclusion has been supported by subsequent gel filtration studies using Fab' anti-Factor VIII prepared from W. C. IgG. Complexes formed with this reagent indicate an antigen size of $\cong 115.000$ daltons. $^{2}$

The very small concentration of large (void volume) immune complexes in these studies is consistent with our previous observations using radiolabeled IgG that has anti-Factor VIII activity (5). Those studies were carried out under conditions of marked antigen excess with the expectation that such conditions would maximize the formation of large immune complexes that could be detected in void volume fractions. The findings reported here indicate that these conditions have the opposite effect, however, and that void volume im-

\footnotetext{
${ }^{2}$ Hoyer, L. W., J. Lazarchick, and N. C. Trabold. Manuscript in preparation.
}

mune complexes are present in greater concentration when there is antibody excess. It will be of interest to determine if labeled anti-Factor VIII IgG of higher specific activity can be identified in large immune complexes formed in antibody excess.

Although the properties of human anti-Factor VIII have been clarified to some extent by these studies, their implications for Factor VIII structure may prove to be more critical. It will be important to examine how the presence of human anti-Factor VIII facilitates the apparent separation of the two components of Factor VIII, an interpretation which is consistent with studies which have been reported by Zimmerman and Edgington (30) and by Hougie et al. (31). Studies with human anti-Factor VIII may provide a new way to examine the interaction of these components, a central issue in the understanding of the relationship of structure and function in Factor VIII.

\section{ACKNOWLEDGMENTS}

These studies were supported in part by research grants HL 16626 and 16872 from the National Heart, Lung and Blood Institute of the National Institutes of Health.

\section{REFERENCES}

1. Shapiro, S. S. 1967. The immunologic character of acquired inhibitors of antihemophilic globulin (Factor VIII) and the kinetics of their interaction with Factor VIII. J. Clin. Invest. 46: 147-156.

2. Feinstein, D. I., S. I. Rapaport, and M. M. Y. Chong. 1969. Immunologic characterization of 12 Factor VIII inhibitors. Blood. 34: 85-90.

3. Shapiro, S. S., and M. Hultin. 1975. Acquired inhibitors to coagulation factors. Semin. Thromb. Hemostasis. 1: 336-385.

4. Robboy, S. J., E. J. Lewis, P. H. Schur, and R. W. Colman. 1970. Circulating anticoagulants to Factor VIII. Am. J. Med. 49: 742-752.

5. Hoyer, L. W. 1972. Immunologic studies of antihemophilic factor (AHF, Factor VIII). III. Comparative binding properties of human and rabbit anti-AHF. Blood. 39: 481-489.

6. Hoyer, L. W. 1973. Immunologic properties of antihemophilic factor. Prog. Hematol. 8: 191-221.

7. Allain, J. P., and D. Frommel. 1973. Antibodies to Factor VIII. I. Variation in stability of antigen-antibody complexes in hemophilia A. Blood. 42: 437-444.

8. Lavergne, J. M., D. Meyer, and H. Reisner. 1976. Characterization of human anti-Factor VIII antibodies purified by immune complex formation. Blood. 48: 931-939.

9. Breckenridge, R. T., and O. D. Ratnoff. 1962. Studies on the nature of the circulating anticoagulant directed against antihemophilic factor: with notes on an assay for antihemophilic factor. Blood. 20: 137-149.

10. Hoyer, L. W. 1972. Immunologic studies of antihemophilic factor (AHF, Factor VIII). IV. Radioimmunoassay of AHF antigen. J. Lab. Clin. Med. 80: 822-833.

11. Kasper, C. K., L. M. Aledort, R. B. Counts, J. R. Edson, J. Fratantoni, D. Green, J. W. Hampton, M. W. Hilgartner, J. Lazerson, P. H. Levine, C. W. McMillan, J. G. Pool, S. S. Shapiro, N. R. Shulman, J. van Eys. 
1975. A more uniform measurement of Factor VIII inhibitors. Thromb. Diath. Haemorrh. 34: 869-871.

12. Katz, A. J., and E. E. Morse. 1972. Factor V activity in fresh frozen and cryoprecipitate-removed plasma. Vox Sang. 22: 39-44.

13. Rickles, F. R., L. W. Hoyer, M. E. Rick, and D. J. Ahr. 1976. The effect of epinephrine infusion in patients with von Willebrand's disease. J. Clin. Invest. 57: 1618-1625.

14. Hoyer, L. W., and R. T. Breckenridge. 1968. Immunologic studies of antihemophilic factor (AHF, Factor VIII): cross-reacting material in a genetic variant of hemophilia A. Blood. 32: 962-971.

15. Zimmerman, T. S., O. D. Ratnoff, and A. E. Powell. 1971. Immunologic differentiation of classic hemophilia (Factor VIII deficiency) and von Willebrand's disease. J. Clin. Invest. 50: 244-254.

16. Mancini, G., A. D. Carbonara, and J. F. Heremans. 1965. Immunochemical quantitation of antigen by a single radial immunodiffusion. Int. J. Immunochem. 2: 235254.

17. Rick, M. E., and L. W. Hoyer. 1977. Thrombin activation of Factor VIII: the effect of inhibitors. Br. J. Haematol. 36: $585-597$.

18. Cooper, H. A., F. F. Reisner, M. Hall, and R. H. Wagner. 1975. Effects of thrombin treatment on preparations of Factor VIII and the $\mathrm{Ca}^{++}$-dissociated small active fragment. J. Clin. Invest. 56: 751-760.

19. Poon, M. C., and O. D. Ratnoff. 1976. Evidence that functional subunits of antihemophilic factor (Factor VIII) are linked by noncovalent bonds. Blood. 48: 87-94.

20. Switzer, M. E., and P. A. McKee. 1976. Studies on human antihemophilic factor. Evidence for a covalently linked subunit structure. J. Clin. Invest. 57: 925-937.

21. Austen, D. E. G. 1976. Factor VIII. Nature (Lond.). 262: $91-92$.

22. Owen, W. G., and R. H. Wagner. 1972. Antihemophilic factor: separation of an active fragment following dissociation by salts or detergents. Thromb. Diath. Haemorrh. 27: 502-515.

23. Rick, M. E., and L. W. Hoyer. 1973. Immunologic studies of antihemophilic factor (AHF, Factor VIII). V. Immunologic properties of AHF subunits produced by salt dissociation. Blood. 42: 737-747.

24. Weiss, H. J., and L. W. Hoyer. 1973. Dissociation of antihemophilic factor procoagulant activity from the von Willebrand factor. Science (Wash. D. C.). 182: 11491151.

25. Rick, M. E., and L. W. Hoyer. 1974. Activation of low molecular weight fragment of antihemophilic factor (Factor VIII) by thrombin. Nature (Lond.). 252: 404-405.

26. Rick, M. E., and L. W. Hoyer. 1975. Molecular weight of human Factor VIII procoagulant activity. Thromb. Res. 7: 909-916.

27. Bloom, A. L., I. R. Peake, and J. C. Giddings. 1973. The presence and reactions of high and lower-molecularweight procoagulant Factor VIII in the plasma of patients with von Willebrand's disease after treatment: significance for a structural hypothesis for Factor VIII. Thromb. Res. 3: 389-404.

28. Shapiro, S. S. 1975. Characterization of Factor VIII antibodies. Ann. N. Y. Acad. Sci. 240: 350-361.

29. Weiss, H. J., J. Rodgers, and H. Brand. 1973. Defective ristocetin-induced platelet aggregation in von Willebrand's disease and its correction by Factor VIII. J. Clin. Invest. 52: 2697-2707.

30. Zimmerman, T. S., and T. S. Edgington. 1973. Factor VIII coagulant activity and Factor VIII-like antigen: independent molecular entities. J. Exp. Med. 138: 1015-1020.

31. Hougie, C., R. B. Sargeant, J. E. Brown, and R. F. Baugh. 1974. Evidence that Factor VIII and the ristocetin aggregating factor $\left(\mathrm{VIII}_{\text {Rist }}\right)$ are separate molecular entities. Proc. Soc. Exp. Biol. Med. 147: 58-61. 